Actas del Seminario Internacional Destinos Turísticos Inteligentes:

nuevos horizontes en la investigación y gestión del turismo

Universidad de Alicante, 26 y 27 de octubre de 2017

\title{
Construção da Rota Estratégica do Setor de Turismo para o Estado de Santa Catarina (Brasil): Um Olhar para 2022
}

\author{
Alexandre Augusto Biz \\ Universidade Federal do Paraná - Brasil \\ Departamento de Turismo \\ bizdetur@gmail.com \\ Carlos Cappelini \\ Girus Soluções em Turismo - Brasil \\ cappelini@gmail.com \\ Carlos Ricardo Rossetto \\ Universidade do Vale do Itajaí - Brasil \\ Departamento de Administração \\ rossetto@univali.br
}

Luciane Camilotti

Senai SC/FIESC - Brasil

Observatório de Inteligência Industrial da FIESC

luciane.camilotti@sc.senai.br

Sidnei Manoel Rodrigues

Senai SC/FIESC - Brasil

Observatório de Inteligência Industrial da FIESC

sidneimr@fiesc.com.br

\section{Resumo}

A construção da Rota Estratégica do Setor de Turismo para o Estado de Turismo de Santa Catarina (Brasil) teve como objetivo ampliar a competitividade do Turismo, por meio do Programa de Desenvolvimento Industrial Catarinense - PDIC, para identificar os setores indutores de desenvolvimento, indicar as visões de futuro para cada setor, traçar o caminho mais provável para atingi-la, e promover a articulação de todas as partes interessadas. Foram analisados os conceitos e modelos de Destinos Turísticos Inteligentes - DTI, a visão de turismo como uma plataforma de negócios 
Actas del Seminario Internacional Destinos Turísticos Inteligentes:

nuevos horizontes en la investigación y gestión del turismo

Universidad de Alicante, 26 y 27 de octubre de 2017

por Biz (2014) e os pressupostos de integração regional executados por outros Países. A metodologia proposta, baseada em pesquisa exploratório e descritiva, buscou analisar a situação atual (onde estamos), o futuro desejado (para onde queremos ir), desafios (o que impede este futuro) e as soluções (o que necessitamos para enfrentar os desafios), divididas em seis fases com a participação de consultores e especialistas, realizada entre setembro de 2015 a outubro de 2016. Como resultado principal tem-se a definição da consolidação do Estado de Santa Catarina como DTI para o ano de 2022 observando a sustentabilidade, incentivo fiscal, mobilidade e integração. A implementação das ações apresentada está em fase da construção de um consórcio multidisciplinar envolvendo setor público (legislativo, executivo e judiciário), federações setoriais, instituições de ensino superior, centros de inovação, e comunidade para o desenvolvimento tecnológico desta plataforma de DTI.

Palavras-chaves: Rota Estratégica, Turismo, Destinos Turísticos Inteligentes, Plataforma de Negócios, Santa Catarina

\section{Introdução}

Nos últimos três anos, a Federação das Indústrias do Estado de Santa Catarina - FIESC tem construído com demais parceiros estratégicos o Programa de Desenvolvimento Industrial Catarinense - PDIC2022, com a proposta de identificar os setores indutores de desenvolvimento, identificar as visões de futuro para cada setor, traçar o caminho mais provável para atingi-la, promover a articulação de todas as partes interessadas (FIESC, FECOMERCIO SC \& SEBRAE/SC, 2016).

Ao todo, foram priorizados 16 Setores Portadores de Futuro para o Estado de Santa Catarina, nos quais se construiu rotas estratégicas dos setores e das áreas para esboçar visões de futuro para cada um dos setores e áreas selecionados, elaborar agenda convergente de ações de todas as partes interessadas para concentrar esforços e investimentos, identificar tecnologias-chave para a indústria de Santa Catarina e elaborar mapas com as trajetórias possíveis e desejáveis para cada um dos setores ou áreas estratégicas.

A construção da Rota Estratégica do Setor de Turismo para o Estado de Turismo de Santa Catarina (Brasil) foi desenvolvida, entre setembro de 2015 a setembro de 2016, a partir do planejamento estratégico da FIESC e com a participação da Federação do Comércio de Bens, Serviços e Turismo de 
Actas del Seminario Internacional Destinos Turísticos Inteligentes:

nuevos horizontes en la investigación y gestión del turismo

Universidad de Alicante, 26 y 27 de octubre de 2017

Santa Catarina - FECOMERCIO SC, do Serviço Brasileiro de Apoio às Micro e Pequenas Empresas de Santa Catarina - SEBRAE/SC, dos representantes do setor público e privado de Turismo, terceiro setor e das Instituições de Ensino Superior do Estado de Santa Catarina.

O objetivo desta rota foi o de ampliar a competitividade do Turismo, por meio do Programa de Desenvolvimento Industrial Catarinense - PDIC, para identificar os setores indutores de desenvolvimento, indicar as visões de futuro para cada setor, traçar o caminho mais provável para atingi-la, e promover a articulação de todas as partes interessadas (FIESC, FECOMERCIO SC \& SEBRAE/SC, 2016).

Para tanto, foram escolhidos cinco macrossegmentos de turismo para o desenvolvimento do projeto sendo o turismo de orla, turismo em áreas naturais, parques Temáticos, MICE - Meetings (Encontros), Incentives (Incentivos), Conferences (Conferências), Exhibitions (Feiras), e regiões históricas e turísticas.

Estes macrossegmentos foram definidos a partir da construção de conceitos e definições dos segmentos da oferta turística para o país realizados pelo Ministério do Turismo ao longo dos últimos dez anos e que, respectivamente, integram diversos segmentos e nichos de mercado, tendo como referência projeto realizado por Todesco et. al. (2014).

No que concerne ao desenvolvimento das prioridades para a Rota Estratégica do Setor de Turismo, foram adicionadas à metodologia os conceitos de Destinos Turísticos Inteligentes - DTI, a visão de turismo como uma plataforma de negócios por Biz (2014), os pressupostos de integração regional do Plano de Ação para o Desenvolvimento do Turismo de Portugal 2020 e a estratégia para elaboração do Plano de Ações do Turismo 2020 da Austrália concebido pelo Departamento de Recursos, Energia e Turismo (FIESC, FECOMERCIO SC \& SEBRAE/SC, 2016).

Para a construção da rota, buscou-se identificar as sinergias e as oportunidades a partir das visões estratégicas das rotas realizadas nos setores de Tecnologia da Informação e Comunicação; Têxtil e Confecção; Saúde; Produtos Químicos e Plásticos; Agroalimentar; Bens de Capital; Celulose e Papel; Cerâmica; Meio Ambiente; Indústrias Emergentes; Energia; Economia do Mar; Construção Civil; Metalmecânica e Metalúrgica; e, Móveis e Madeira.

Por fim, a base de análise se pautou por dez indicadores (definidos como drivers) da metodologia do World Economic Forum - WEF (2015) sobre o Índice de Competitividade em Viagem e Turismo, como: i) ambiente de 
Actas del Seminario Internacional Destinos Turísticos Inteligentes:

nuevos horizontes en la investigación y gestión del turismo

Universidad de Alicante, 26 y 27 de octubre de 2017

negócios; ii) segurança e proteção; iii) saúde e higiene; iv) recursos humanos e mercado de trabalho; v) facilidade de tecnologia da informação e comunicação; vi) governança; vii) sustentabilidade ambiental; viii) infraestrutura geral e turística; ix) recursos naturais; $\mathrm{x}$ ) recursos culturais (FIESC, FECOMERCIO SC \& SEBRAE/SC, 2016).

\section{Destinos turísticos inteligentes}

Del Chiappa e Baggio (2015) ressaltam que o conceito de destinos turísticos inteligentes - DTI, é recente e emerge das bases conceituais de cidades inteligentes. Fazem uma leitura sobre destinos turísticos como um sistema de network entre diversos stakeholders que realizam serviços para os turistas, suportados por uma infraestrutura tecnológica destinada a criar um ambiente digital no qual suporta cooperação, compartilhamento de conhecimento e inovação aberta.

Corroboram Solsona e Giner (2015) ao descreverem que os destinos turísticos possuem particularidades que devem ser compreendidos e, que dão subsídios para a discussão acerca de DTI, sendo:

- Rápida adoção das tecnologias de informação e comunicação - TIC, por parte dos consumidores de turismo (demanda);

- Alta penetração das TICs pelas empresas que atuam no mercado turístico;

- Olhar transversal - observando a qualidade de vida, meio ambiente e a mobilidade que condicionam a competitividade das empresas e do destino turístico;

- Mercado majoritariamente constituídos por Pequenas e Microempresas (PMEs) que possuem dificuldades em apropriar-se de inovação e conhecimento necessárias para competir e se consolidar no mercado;

- Mudança no modelo de gestão do destino turístico para acompanhar a dinâmica da geração de informação pelos DTI;

- A integração entre turismo e TIC como estratégia de desenvolvimento e por sua vez, consolidar-se em novos modelos de negócios turísticos.

Portanto, o inter-relacionamento dos fatores como tecnologia, demanda eficiente, competitividade, mudanças na gestão empresarial (privada e pública) 
Actas del Seminario Internacional Destinos Turísticos Inteligentes:

nuevos horizontes en la investigación y gestión del turismo

Universidad de Alicante, 26 y 27 de octubre de 2017

e novos modelos de negócios, e sustentabilidade são fundamentais para o desenvolvimento de iniciativas de DTI (INVAT.TUR, 2015).

Para a SEGITTUR (2012) o conceito de destinos turísticos inteligentes - DTI, refere-se a um destino turístico inovador, consolidado sobre uma infraestrutura tecnológica de vanguarda, que garanta o desenvolvimento sustentável do território turístico, acessível a todos, que facilita a interação e integração do visitante com o entorno e incrementa a qualidade da sua experiência nos destinos, melhorando também a qualidade de vida do Munícipe.

Zhu, Zhang \& Li (2014, apud Buhalis \& Amaranggana, 2015) descrevem que o desenvolvimento de destinos turísticos inteligentes traz benefícios para a indústria do turismo ao possibilitar conveniente acessos a informações entre as organizações de turismo e os turistas através de uma plataforma centralizada e integrada de dados.

Buhalis \& Amaranggana (2015) descrevem que trazer inteligência aos destinos turísticos requer que os mesmos estejam interconectados com múltiplo stakeholders através de uma plataforma dinâmica de tecnologia de informação e comunicação a fim de apoiar o intercâmbio rápido de informações sobre as atividades turísticas.

Ivars, Solsona \& Giner (2015) ressaltam que os destinos turísticos inteligentes devem construir um projeto amplo que incorpore cinco bases fundamentais, sendo a governança, sustentabilidade, conectividade, sistema de informação e, por fim, a inovação, baseado no desenvolvimento flexível, que tenha escala e adaptado a cada território.

López e García (2015) citam que destino turístico inteligente é um espaço inovador consolidado sobre a base de um território comprometido com fatores como meio ambiente, cultural e socioeconômico, com uma infraestrutura tecnológica de vanguarda.

Vargas-Sánchez (2016) fez um recorte sobre conceitos sobre DTI, conforme apresentado no quadro 1. 
Actas del Seminario Internacional Destinos Turísticos Inteligentes: nuevos horizontes en la investigación y gestión del turismo

Universidad de Alicante, 26 y 27 de octubre de 2017

Quadro 1. Conceitos de DTI

\begin{tabular}{|l|l|}
\hline \multicolumn{1}{|c|}{ Autores } & \multicolumn{1}{c|}{ Conceitos } \\
\hline López de Ávila (2015) & $\begin{array}{l}\text { Uma iniciativa do destino turístico, construir uma } \\
\text { infraestrutura de estado da arte em tecnologia, garantindo o } \\
\text { desenvolvimento sustentável das áreas turísticas, acessíveis } \\
\text { a qualquer pessoa, que facilita a interação e integração } \\
\text { do visitante nos seus arredores, aumenta a qualidade da } \\
\text { experiência no destino, e melhore a qualidade de vida dos } \\
\text { moradores. }\end{array}$ \\
\hline $\begin{array}{l}\text { Gretzel, Sigala, Xiang \& } \\
\text { Koo (2015) }\end{array}$ & $\begin{array}{l}\text { Como o turismo apoiado por esforços integrados em um } \\
\text { destino para coletar e agregar/aproveitar dados derivados de } \\
\text { infraestrutura física, conexões sociais, fontes governamentais, } \\
\text { organizacionais e corpos/mentes humanos em combinação } \\
\text { com o uso de tecnologias avançadas para transformar esses } \\
\text { dados em experiências no local e proposições de valor de } \\
\text { negócios com um foco claro na eficiência, sustentabilidade e } \\
\text { enriquecimento de experiências. }\end{array}$ \\
\hline $\begin{array}{l}\text { Gretzel, Werthner, Koo \& } \\
\text { Lamsfus (2015) }\end{array}$ & $\begin{array}{l}\text { Conceituar o destino inteligente dentro da idéia mais ampla } \\
\text { de um ecossistema de turismo inteligente, formado, também } \\
\text { e em conjunto, por tecnologias inteligentes e cidades } \\
\text { inteligentes. Esse ecossistema nutre novos modelos de } \\
\text { negócios, novos paradigmas de interação e até novas espécies } \\
\text { de turismo negócios, tornando muito difícil a delimitação de } \\
\text { seus limites. }\end{array}$ \\
\hline
\end{tabular}

Fonte: Adaptado de Vargas-Sánchez (2016)

Vargas-Sánchez (2016) ao fazer suas considerações acerca dos estudos sobre os conceitos de DTI, afirma a necessidade de mudança na gestão do turismo (em destaque setor público), da questão do capital tecnológico TIC (ambiente para desenvolvimento), capital humano (educação/formação/ pesquisa e desenvolvimento) e criação de valores (vantagem competitiva).

Em relação aos conceitos de DTI até aqui apresentados, destaca-se o de Gretzel, Werthner, Koo \& Lamsfus (2015) ao definir o turismo como um ecossistema inteligente.

\section{Turismo como plataforma de negócios}

Corroborando com Gretzel et. at. (2015, apud Vargas-Sánchez, 2016) que definiu o turismo como um ecossistema inteligentes, Biz (2014) apresenta um olhar do turismo como uma plataforma de negócios tem como premissa a visão denominada «um-para-muitos» representada na figura 1 . É a 
Actas del Seminario Internacional Destinos Turísticos Inteligentes:

nuevos horizontes en la investigación y gestión del turismo

Universidad de Alicante, 26 y 27 de octubre de 2017

capacidade de maximizar a participação dos diversos atores da cadeia produtiva do turismo na formação de produtos e serviços turísticos que facilitem a tomada de decisão por parte dos consumidores.

A proposta da plataforma de negócios em turismo interage direta e indiretamente com os diversos conceitos de DTI, em especial a Gretzel, Werthner, Koo \& Lamsfus (2015) e Vargas-Sánchez (2016) quanto ecossistema, capital tecnológico - TIC (ambiente para desenvolvimento), capital humano (educação/formação/pesquisa e desenvolvimento) e criação de valores (vantagem competitiva).

A base desta plataforma de negócios está estruturada no conceito de Gawer (2010, apud FIESC, FECOMERCIO SC \& SEBRAE/SC, 2016), que descreve as plataformas como aplicações em indústrias ou atividades que geram produtos, serviços ou tecnologias, e que são desenvolvidas por uma ou mais empresas servindo como base para que outras empresas possam construir produtos, serviços ou tecnologias complementares e inovadoras, ou seja, um ambiente sistêmico e integrado capaz de potencializar o desenvolvimento e a inovação.

Figura 1. Desenho da Plataforma de Negócios em Turismo

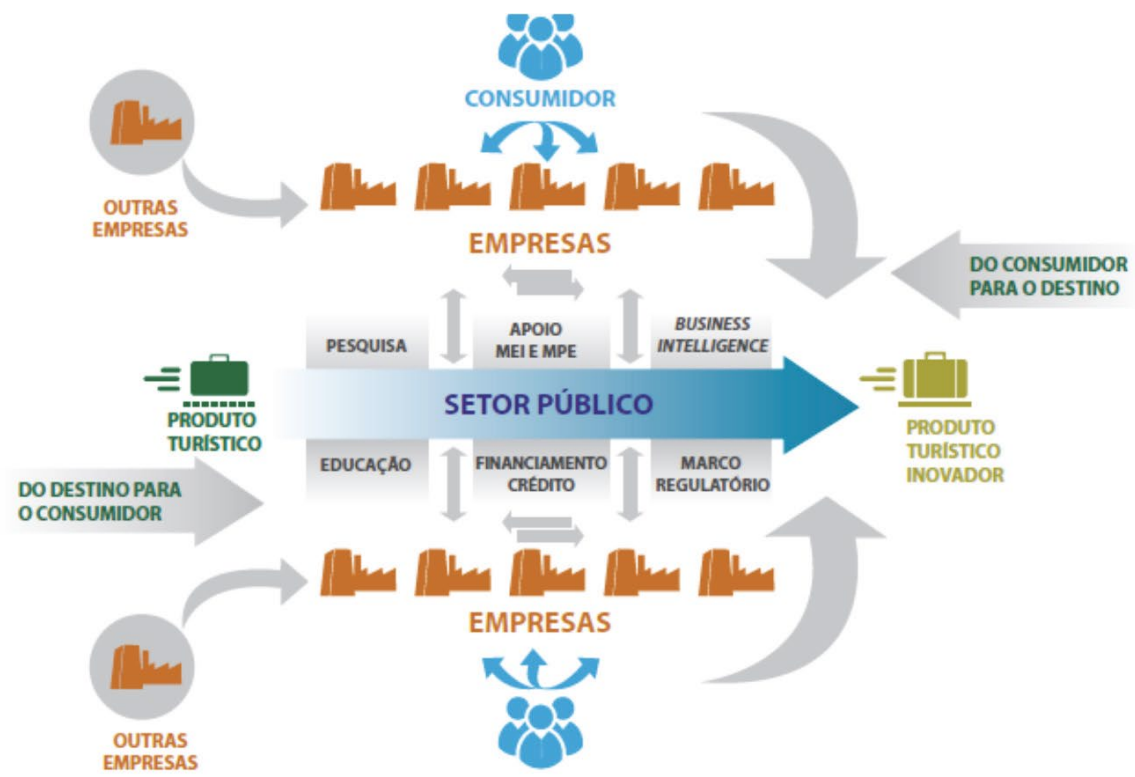

Fonte: Biz (2014, apud TODESCO et. al. 2014, p. 89) 
Actas del Seminario Internacional Destinos Turísticos Inteligentes:

nuevos horizontes en la investigación y gestión del turismo

Universidad de Alicante, 26 y 27 de octubre de 2017

As potencialidades dos macrossegmentos não devem ser vistas de forma individual (foco input: insumo), ao contrário, a integração entre os seus componentes permite a formação de produtos e serviços turísticos que agreguem valor competitivo para o destino turístico, para os stakeholders e para a comunidade (foco output: resultados dos negócios).

Primeiramente, o setor público exerce papel fundamental neste processo ao definir o turismo como objeto de desenvolvimento socioeconômico, cultural e ambiental, seja em nível Municipal, Estadual ou Federal, e atuar por meio de políticas públicas na integração transversal do turismo com as diversas áreas de desenvolvimento.

Requer, de forma integrada, políticas públicas em seis eixos:

- Educação - formação de capital humana, desde a educação básica a universidade;

- Pesquisa - incentivo a pesquisa e inovação, formação de polos tecnológicos (clusters de TIC);

- Apoio as PMEs e MEI - favorecimento na abertura e consolidação de Pequenas e Microempresas e Microempreendedor Individual, para a geração de empregos e fortalecimento dos prestadores de serviços turísticos e indiretos (cadeia produtiva);

- Financiamento e Crédito - abertura e flexibilização de linhas de financiamento e crédito para a PMEs e MEI para adoção de tecnologias e melhorias de infraestrutura física, equipamentos e pessoal, observando o comportamento do consumidor turístico;

- Business Intelligence - implementação de um sistema de inteligência turística, uma plataforma de gestão de conhecimento organizacional;

- Marco regulatório - leis que possibilitem o desenvolvimento, a inovação, o empreendedorismo dando ao setor público e privado um mínimo de segurança jurídica.

O objetivo central da plataforma está em estimular e ampliar o valor agregado de bens e serviços turísticos, a formação atual e futura de pessoas para atuar no setor, a formalização de MEl e ME, e a busca pela inovação, beneficiando todos os atores envolvidos de forma direta ou complementar na cadeia de valor do turismo, e principalmente, a mudança no modelo de gestão de destinos turísticos. 
Actas del Seminario Internacional Destinos Turísticos Inteligentes: nuevos horizontes en la investigación y gestión del turismo

Universidad de Alicante, 26 y 27 de octubre de 2017

\section{Plano de ação para o desenvolvimento do turismo de Portugal 2020}

Iniciativa corporizada num Plano de Ação para o Desenvolvimento do Turismo em Portugal para o período de programação comunitária 2014-2020, que incluiu várias perspectivas setoriais e integrou as diferentes especificidades e estratégias regionais. Buscou-se estabelecer objetivos e prioridades de investimentos para o turismo em Portugal e suas regiões turísticas com visão para o ano de 2020

O plano refletiu aquilo que os agentes do tecido empresarial do turismo, do desenvolvimento regional, do sistema científico e tecnológico nacional e da promoção turística de todo o território nacional consideraram prioritário ser apoiado pelos fundos comunitários para o turismo de Portugal, assegurando o alinhamento estratégico entre as estratégias e os financiamentos (Portuga. Turismo de Portugal, 2014).

Figura 2. Turismo 2020: Integração das Especificidades Regionais
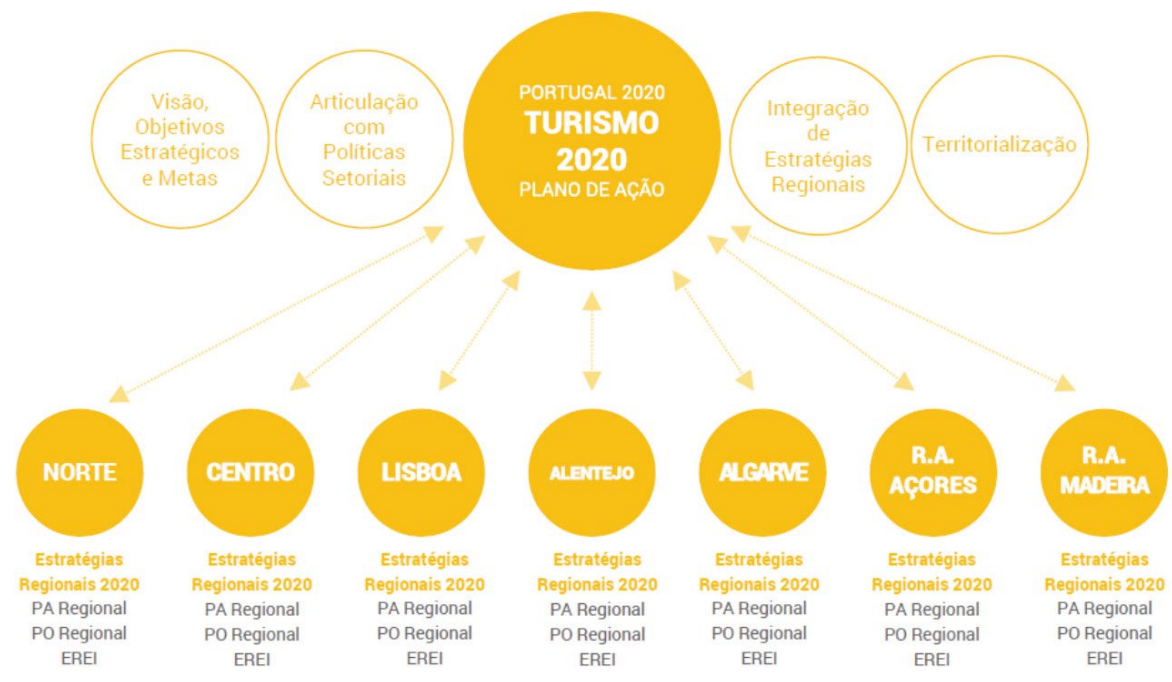

Fonte: Portugal. Turismo de Portugal (2014:9)

Entre os objetivos propostos estavam (Portugal. Turismo de Portugal, 2014): 
Actas del Seminario Internacional Destinos Turísticos Inteligentes:

nuevos horizontes en la investigación y gestión del turismo

Universidad de Alicante, 26 y 27 de octubre de 2017

- Fomentar uma articulação entre promotores e projetos, promovendo, nomeadamente uma melhor articulação entre os setores público e privado;

- Promover uma maior seletividade e uma melhor afetação dos fundos comunitários para o turismo no âmbito do Portugal 2020;

- Criar as condições para o reconhecimento de uma Estratégia de Eficiência Coletiva no Portugal 2020 - destina-se, assim, à constituição do Cluster Estratégico do Turismo no Portugal 2020; e

- Proporcionar aos promotores de projetos (públicos e privados) e às Autoridades de Gestão dos Programas Operacionais um quadro referencial sobre as prioridades consideradas prioritárias em matéria de cofinanciamento comunitário para o turismo.

Em suma, a proposta teve como propósito criar uma estratégia nacional e regionais de turismo, com regulamentação específica, criar condições para uma estratégia de eficiência coletiva baseada em uma triangulação: estratégia, recursos financeiros e mobilização e compromisso (vontade).

\section{Plano turismo Austrália 2020}

O plano nacional de estratégia de turismo Austrália 2020, foi iniciado em dezembro de 2009 e finalizado em 2011. Entre os anos de 2012 a 2014 foram definidas as estratégias prioritárias, e nos de 2015 a 2017 período para mensurar os resultados, conforme descrito na figura 3 (Australian Government. Tourism 2020).

Para FIESC, FECOMERCIO SC \& SEBRAE/SC (2016:13) «o Plano 2020 da Austrália representa um nível sem precedentes de cooperação entre a indústria, a comunidade e os Governos (Central e Regionais) para abordar as barreiras de crescimento da indústria do turismo, melhorando a sua capacidade produtiva.»

Foram determinadas seis áreas estratégicas para o plano Austrália Turismo 2020, trabalhadas dia-a-dia integradas entre o setor produtivo do turismo e setor público com a proposta de converter a demanda (real e potencial) em visitação, desenvolver produtos turísticos e tornar o turismo da Austrália mais competitivo. As seis áreas estratégicas foram definidas como (Australian Government. Tourism 2020): 
Actas del Seminario Internacional Destinos Turísticos Inteligentes: nuevos horizontes en la investigación y gestión del turismo Universidad de Alicante, 26 y 27 de octubre de 2017

- Ampliar a demanda da Ásia;

- Construir a competitividade digital;

- Incentivar o investimento e implementar a reforma regulatória;

- Certificar-se de que o sistema de transporte turístico (a partir da Austrália, para a Austrália e dentro da Austrália) suporta o crescimento da demanda;

- Aumentar a oferta de trabalho, a oferta de formação e a participação indígena no turismo; e

- Fortalecer a resiliência, a produtividade e a qualidade do setor produtivo do turismo.

Figura 3. Plano de Implementação do Plano Turismo Austrália 2020

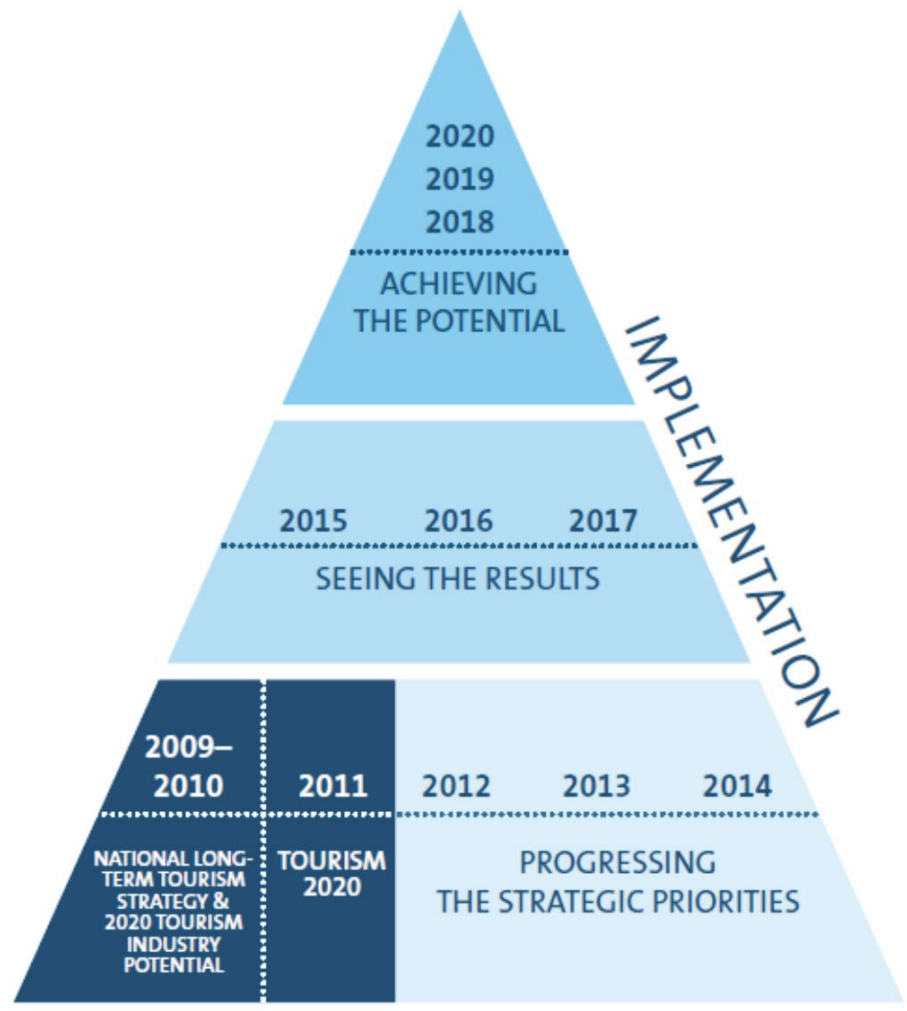

Fonte: Australian Government. Tourism 2020 (2011) 
Actas del Seminario Internacional Destinos Turísticos Inteligentes:

nuevos horizontes en la investigación y gestión del turismo

Universidad de Alicante, 26 y 27 de octubre de 2017

Em suma, apontam a necessidade de um marco legal, integração entre os stakeholders, visão sistêmica, pesquisa e inovação e modelo de gestão de destino turístico.

\section{Metodologia}

Caracteriza-se como pesquisa exploratória na construção dos conceitos centrais quanto destinos turísticos inteligentes, de plataforma de negócios e modelos de planos de turismo internacional. Descritiva na realização de seis fases para a construção da rota estratégica de turismo quanto ao recorte geográfico do Estado de Santa Catarina, estudo socioeconômico, definição dos macrossegmentos prioritários, estudos e tendências, validações com especialistas e, por fim, a consolidação e análise dos resultados.

A metodologia proposta pela FIESC, FECOMERCIO SC \& SEBRAE/SC (2016) buscou analisar a situação atual (onde estamos), o futuro desejado (para onde queremos ir), desafios (o que impede este futuro) e as soluções (o que necessitamos para enfrentar os desafios), divididas em seis fases.

Quadro 2. Fases da Metodologia

\begin{tabular}{|l|l|l|}
\hline FASE & \multicolumn{1}{|c|}{ ATIVIDADES } & \multicolumn{1}{|c|}{ Responsáveis } \\
\hline 01 & $\begin{array}{l}\text { Análise situacional das12 regiões turísticas reconhecidas } \\
\text { pelo Ministério de Turismo - MTur: Caminho dos Canyos, } \\
\text { Caminhos dos Príncipes, Caminhos da Fronteira, Caminhos } \\
\text { do Alto Vale, Costa Verde \& Mar, Encantos do Sul, Grande } \\
\text { Florianópolis, Grande Oeste, Serra Catarinense, Vale das } \\
\text { Águas, Vale do Contestado, Vale Europeu. }\end{array}$ & $\begin{array}{l}\text { Consultores e } \\
\text { representantes } \\
\text { FIESC, } \\
\text { FECOMERCIO SC } \\
\text { e SEBRAE }\end{array}$ \\
\hline 03 & $\begin{array}{l}\text { Estudo socioeconômico composto por uma análise } \\
\text { da realidade socioeconômica do turismo em âmbito } \\
\text { internacional, nacional e de todo o Estado de Santa Catarina }\end{array}$ & $\begin{array}{l}\text { Análise dos cinco macrossegmentos prioritários para o Estado } \\
\text { definido como Turismo de Orla; Turismo em Áreas Naturais; } \\
\text { Parques Temáticos; Meeting, Incentive, Convetion \& Events - } \\
\text { MICE, e Regiões Históricas e Turísticas. }\end{array}$ \\
\hline $\begin{array}{l}\text { FIESC } \\
\text { FECOMERCIO SC } \\
\text { e SEBRAE }\end{array}$ & $\begin{array}{l}\text { Consultores e } \\
\text { representantes } \\
\text { FIESC, } \\
\text { FECOMERCIO SC } \\
\text { e SEBRAE }\end{array}$ \\
\hline
\end{tabular}


Actas del Seminario Internacional Destinos Turísticos Inteligentes:

nuevos horizontes en la investigación y gestión del turismo

Universidad de Alicante, 26 y 27 de octubre de 2017

\begin{tabular}{|l|l|l|}
\hline 04 & $\begin{array}{l}\text { Estudo de tendências consistiu na investigação de fenômenos } \\
\text { sociais, econômicos, industriais e tecnológicos de impacto } \\
\text { tanto mundial quanto local, identificando as tendências } \\
\text { relacionadas à tecnologia e a experiência turística nos cinco } \\
\text { macrossegmentos prioritários. }\end{array}$ & $\begin{array}{l}\text { Consultores e } \\
\text { representantes } \\
\text { FIESC, } \\
\text { FECOMERCIO SC } \\
\text { e SEBRAE }\end{array}$ \\
\hline 05 & $\begin{array}{l}\text { Validação com os especialistas construída a visão estratégica } \\
\text { para o turismo do Estado de Santa Catarina }\end{array}$ & Especialistas \\
\hline 06 & Construção do Roadmap pelos consultores & $\begin{array}{l}\text { Consultores e } \\
\text { representantes } \\
\text { FIESC, } \\
\text { FECOMERCIO SC } \\
\text { e SEBRAE }\end{array}$ \\
\hline
\end{tabular}

Fonte: Elaboração própria (2016)

Nas fases 01 a 04 também se pautaram na análise de dez indicadores (definidos como drivers) da metodologia do World Economic Forum - WEF (2015) sobre Índice de Competitividade em Viagem e Turismo, como i) ambiente de negócios, ii) segurança e proteção, iii) saúde e higiene, iv) recursos humanos e mercado de trabalho, v) facilidade de tecnologia da informação e comunicação, vi) governança, vii) sustentabilidade ambiental, viii) infraestrutura geral e turística, ix) recursos naturais $\mathrm{e}, \mathrm{x}$ ) recursos culturais.

Estas fases foram desenvolvidas pelos consultores e representantes da FIESC, FECOMERCIO SC \& SEBRAE SC no período de setembro de 2015 a de fevereiro de 2016, e resultou-se na visão sistêmica da construção da rota a partir dos conceitos e estruturas de DTI da SEGITTUR (2014), os cinco macrossegmentos, as demais rotas estratégicas setoriais, e os drivers do WEF, representada na figura 4. 
Actas del Seminario Internacional Destinos Turísticos Inteligentes: nuevos horizontes en la investigación y gestión del turismo

Universidad de Alicante, 26 y 27 de octubre de 2017

Figura 4. Visão Sistêmica da Construção da Rota Estratégica do Setor de Turismo

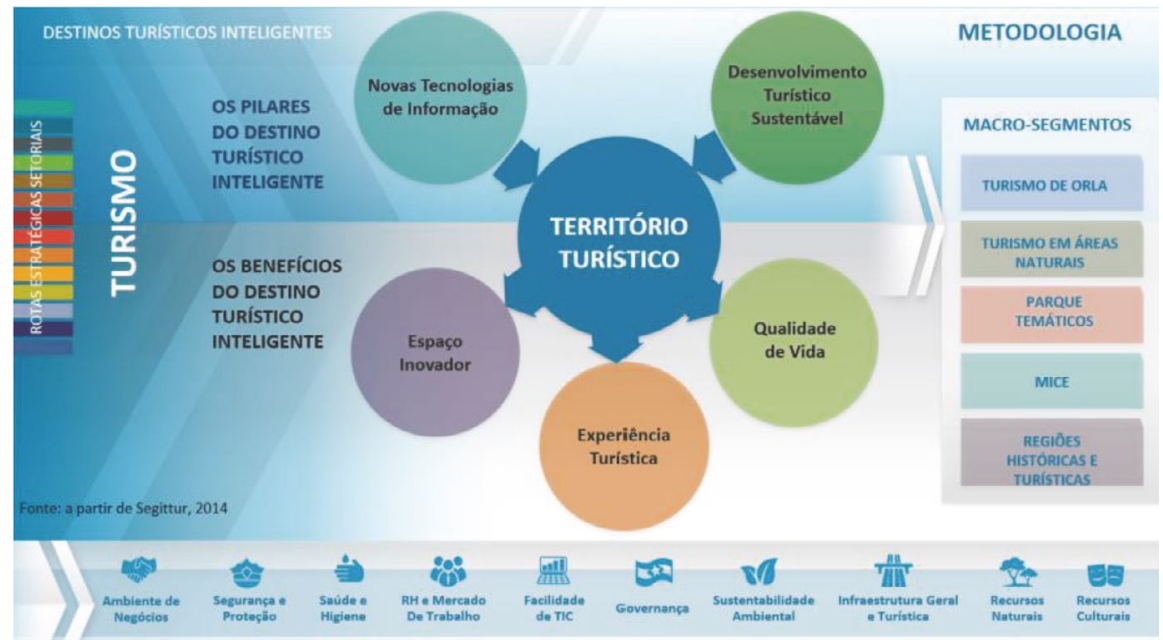

Fonte: FIESC, FECOMERCIO SC \& SEBRAE (2016:10)

Na fase 05, realizada entre os dias 09 e 10 de março de 2016, foram validadas das fases 01 a 04 com os especialistas representantes do setor público, privado e terceiro setor. Inicialmente, foram identificados os fatores críticos (entraves para o crescimento), definidas as ações para os fatores críticos (curto, médio e longo prazo) e a definição da visão do turismo do Estado (futuro do setor).

Por fim, na fase 06 foi realizada para consolidação e análise dos resultados realizada entre abril e setembro de 2016. A partir das vantagens competitivas do turismo do Estado de Santa Catarina por macrossegmentos e, respectivamente, as suas tendências e oportunidades, a construção do roadmap foi desenvolvida observando o turismo como plataforma de negócio, baseado em Biz (2014, apud Todesco et. al, 2014). 
Actas del Seminario Internacional Destinos Turísticos Inteligentes: nuevos horizontes en la investigación y gestión del turismo

Universidad de Alicante, 26 y 27 de octubre de 2017

Figura 5. Turismo como plataforma de negócios

\section{0}

VISĂO DAS DEMAIS ROTAS ESTRATÉGICAS SETORIAIS

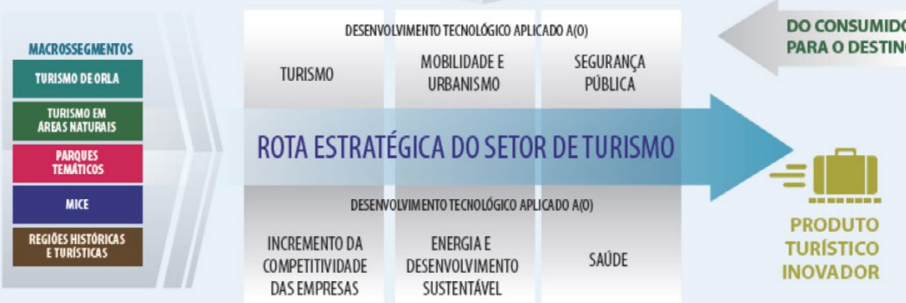

6 EIXOS DESTINOS TURISTICOS INTELIGENTES SEGITTUR

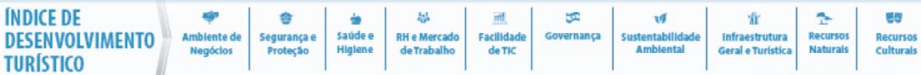

Fonte: Adaptado de Biz (2014, apud FIESC, FERCOMERCIO SC \& SEBRAE, 2016:86)

A base central da rota foi a adaptação de seis eixos estratégicos para destinos turísticos inteligentes, segundo López de Ávila e García Sánchez (2015), tendo como olhar a possibilidade de integração com as demais rotas estratégicas setoriais, representada na figura 5 (FIESC, FECOMERCIO SC \& SEBRAE/SC, 2016).

\section{Análise dos resultados}

$\mathrm{Na}$ fase 05 foram construídas pelos especialistas a visão estratégica para o turismo do Estado de Santa Catarina, «ser reconhecida internacionalmente como destino turístico sustentável, inovador e competitivo, que proporciona experiências diversificadas e memoráveis.» E para a implementação da visão, foram definidos 07 fatores críticos com total de 503 ações divididas em curto, médio e longo prazo, conforme tabela 1. 
Actas del Seminario Internacional Destinos Turísticos Inteligentes:

nuevos horizontes en la investigación y gestión del turismo

Universidad de Alicante, 26 y 27 de octubre de 2017

Tabela 1. Ações para Rota Estratégica por Fatores Críticos

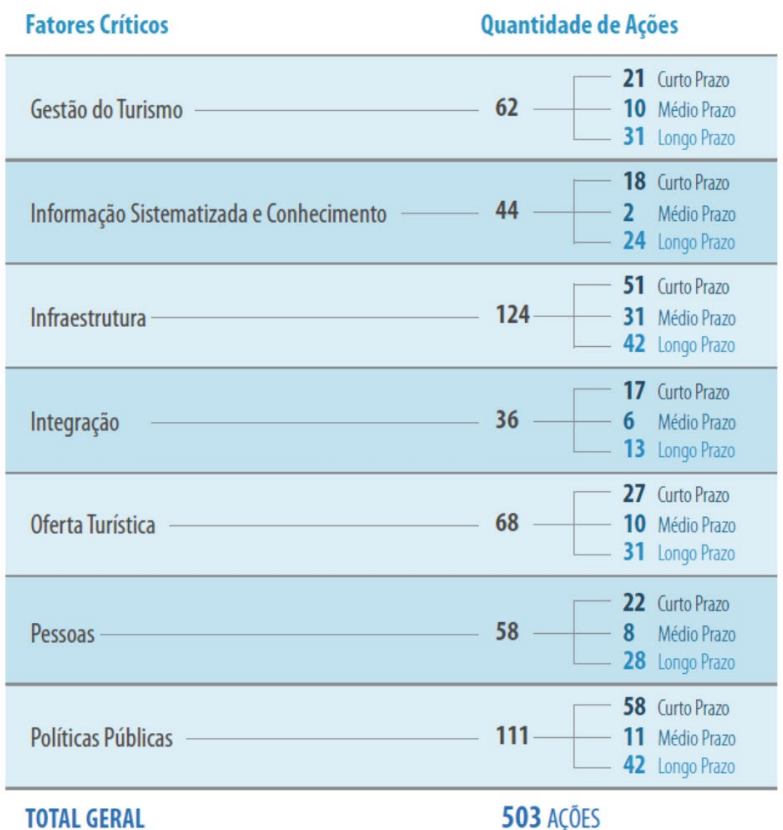

Fonte: FIESC, FECOMERCIO SC, SEBRAE (2016:17)

Percebe-se nos fatores críticos o alinhamento com os conceitos de DTI quanto a gestão do turismo (modelo/estratégia), oferta turística (novos produtos/serviços), pessoas (qualificação/formação), políticas públicas (regulamentação, marco legal), informação sistematizada e conhecimento (inovação, pesquisa, desenvolvimento tecnológico), integração (visão do todo/integração entre destinos) e infraestrutura (acessível a todos).

A partir das análises dos fatores críticos e suas respectivas ações, foi possível visualizar, na fase 06, pelos consultores e representantes da FIESC, FECOMERCIO SC \& SEBRAE/SC oportunidades para o Estado de Santa Catarina iniciando pelo processo de pesquisa e desenvolvimento - P\&D.

O Governo do Estado está em fase de implementação de 13 Centros de Inovação que terão como meta de ativar o ecossistema de inovação, promover a cultura inovadora e empreendedora e viabilizar negócios inovadores 
Actas del Seminario Internacional Destinos Turísticos Inteligentes: nuevos horizontes en la investigación y gestión del turismo

Universidad de Alicante, 26 y 27 de octubre de 2017

com alto potencial de crescimento para transformar a economia da região, sendo estes centros podem atender diretamente a 10 regiões turísticas do estado. Como apontado no estudo, percebeu-se como oportunidade preponderante o alinhamento com a Rota Estratégica do Setor de Tecnologia de Informação e Comunicação (FIESC, FECOMERCIO SC \& SEBRAE/SC, 2016).

A partir disto, foram analisados os 05 macrossegmentos. No macrossegmento Orla, o Estado de Santa Catarina possui aproximadamente $531 \mathrm{~km}$ de litoral, sem contar rios, lagos e outros, sendo referência nacional em produção de embarcações, existindo potencial também no interior do Estado com as hidrelétricas (pequenas, médias e grandes) instaladas e em processo de instalação, que geram lagos os quais poderiam ser utilizados para atividades náuticas. Portanto, observou-se como oportunidade preponderante o alinhamento estratégico com a Rota Estratégica do Setor Economia do Mar, Construção Civil, Meio Ambiente e Energia (FIESC, FECOMERCIO SC \& SEBRAE/SC, 2016).

O macrossegmento Regiões Históricas e Culturais também tem um papel social importante ao promover o diálogo intercultural, a cooperação e a coesão social bem como a paz. O estado de Santa Catarina é diferenciado em termos de produtos históricos, pois cada região é singular. Deve-se observar as contribuições para o crescimento econômico e para as oportunidades geradas por investimentos em atividades correlatas à cultura e ao patrimônio histórico.

Neste macrossegmento foram identificados alguns produtos complementares como arqueologia e paleontologia, cinematográfico, enoturismo, étcnico, eventos artísticos e culturais, religioso, cultura popular e festas populares, gastronomia, intercâmbio, pedagógico, familiar e experiencial. Portanto, observou-se como oportunidade preponderante o alinhamento estratégico com a Rota Estratégica do Setor Agroalimentar, Construção Civil, Meio Ambiente e Economia do Mar (FIESC, FECOMERCIO SC \& SEBRAE/SC, 2016).

Quanto ao macrossegmento MICE, o mercado é promissor em virtude das características socioeconômicas e culturais que demandam a realização de pequenos, médios e grandes eventos e exigem, por parte das empresas e espaços de eventos, a oferta de um serviço inovador e que atenda suas exigências e expectativas.

Por outro lado, o Estado, apesar de pequeno territorialmente possui uma ampla oferta de espaços e centros de eventos distribuídos por todas as 
Actas del Seminario Internacional Destinos Turísticos Inteligentes:

nuevos horizontes en la investigación y gestión del turismo

Universidad de Alicante, 26 y 27 de octubre de 2017

regiões turísticas o setor de eventos no Estado é formado por milhares de empresas que oferecem todo tipo de serviço de eventos. Estas empresas, reunidas em 13 Convention \& Visitors Bureau, têm condição, por meio de planejamento e inovação, de buscar a melhoria contínua nos seus serviços e, desta forma, atender às demandas dos diversos setores e gerar novas oportunidades de negócios (FIESC, FECOMERCIO SC, SEBRAE, 2016).

O macrossegmento de Turismo em Áreas Naturais reúne diversos segmentos de turismo, entre eles: turismo de aventura, turismo de natureza, turismo rural, ecoturismo, além de seus subsegmentos ou nichos de mercado, como o turismo de observação de fauna e flora, espeleoturismo, entre outros (FIESC, FECOMERCIO SC \& SEBRAE/SC, 2016).

É nesse segmento que o Brasil possui a maior competitividade no âmbito mundial, pois ocupa o 1. lugar no ranking de competividade de Viagens e Turismo, no quesito dos recursos naturais, do World Economic Forum - WEF (2017).

O Estado de Santa Catarina possui inúmeras Áreas Naturais Protegidas, entre elas diversas áreas integrantes do Sistema Nacional de Unidades de Conservação - SNUC, em destaque Parque Nacional de Aparados da Serra, Parque Nacional da Serra Geral, Parque Nacional das Araucárias, Parque Nacional de São Joaquim, Parque Estadual da Serra do Tabuleiro, Área de Proteção Ambiental da Baleia Franca, que poderiam atuar em parceria público-privada (PPP) com objetivo de consolidar produtos e serviços turísticos de padrão internacional (FIESC, FECOMERCIO SC \& SEBRAE/SC, 2016).

Este segmento deve estar integrado com os setores agroalimentar, celulose e papel, cerâmico, construção civil, economia do mar, energia, indústrias emergentes, meio ambiente, metalomecânico e metalurgia, produtos químicos e plásticos, tecnologia da informação e comunicação e têxtil \& confecção.

Por fim, o macrossegmento de Parques Temáticos que são considerados empreendimentos de animação inspirados em temas como história, cultura, etnográfico, lúdico ou ambiental. Este segmento possui uma ampla cadeia de serviços integrados direta e indiretamente como, por exemplo, suas atrações, hospedagem, alimentos e bebidas, arquitetura, construção civil, energia, água e saneamento, coleto de lixo reciclável, tecnologias, entre outros (FIESC, FECOMERCIO SC \& SEBRAE/SC, 2016).

Santa Catarina possui um dos mais importantes Parques Temáticos da América Latina (em números de visitantes) e do mundo (avaliação em redes 
Actas del Seminario Internacional Destinos Turísticos Inteligentes: nuevos horizontes en la investigación y gestión del turismo

Universidad de Alicante, 26 y 27 de octubre de 2017

sociais), que geograficamente oferece infraestrutura de apoio de serviços aos seus visitantes. Outro fator a se destacar são os parques aquáticos em praticamente todas as regiões turísticas. Este segmento tem potencial de integração com os setores agroalimentar, construção civil, economia do mar, energia, indústrias emergentes, meio ambiente e tecnologia da informação e comunicação (FIESC, FECOMERCIO SC \& SEBRAE/SC, 2016).

Como conclusão das análises dos cinco macrossegmentos, foi possível construir uma visão integrada das 12 regiões turísticas do Estado de Santa Catarina e demais Rotas Estratégicas Setoriais baseado no modelo Turismo Portugal 2020 representado na figura 6.

Esta visão permitiu confirmar que os 05 macrossegmentos poderiam ser ofertados em todas as 12 regiões turísticas do Estado de Santa Catarina respeitando as suas devidas particularidades, podendo ter o alicerce político, econômico e de infraestrutura dos Municípios definidos como indutores pelo Índice de Desenvolvimento Turístico - IDT, desenvolvido no estudo (FIESC, FECOMERCIO SC \& SEBRAE/SC, 2016).

Figura 6. Visão Integrados dos Macrossegmentos do Setor de Turismo e demais Rotas Estratégicas Setoriais

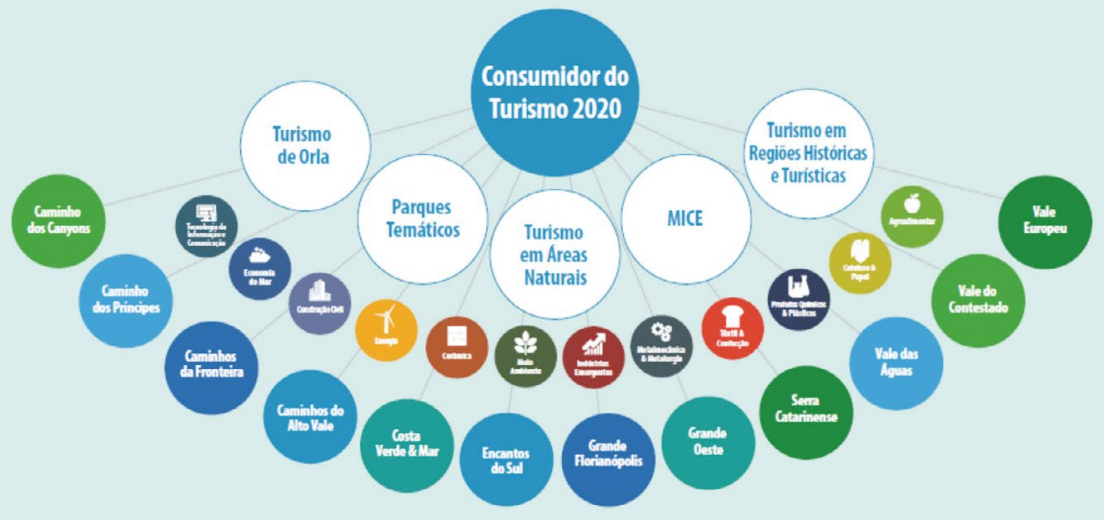

Fonte: FIESC, FECOMERCIO SC \& SEBRAE (2016:84) 
Actas del Seminario Internacional Destinos Turísticos Inteligentes:

nuevos horizontes en la investigación y gestión del turismo

Universidad de Alicante, 26 y 27 de octubre de 2017

A última etapa da fase 06 foi a construção do Roadmap, representada na figura 7, que analisou primeiramente os seis eixos dos destinos turísticos inteligentes adaptados de López \& García (2015) como governança, tecnologias para o turismo, tecnologias para competitividade turística, tecnologias para mobilidade e urbanismo, tecnologias para energia e sustentabilidade, tecnologias para segurança e tecnologias para saúde.

Figura 7. Visão da Construção do Roadmap

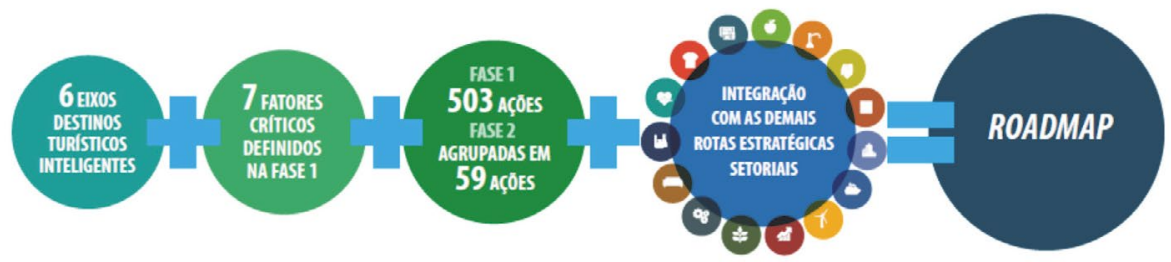

Fonte: FIESC, FECOMERCIO SC \& SEBRAE (2016:88)

Integrou-se nesta análise os 07 fatores críticos definidos na fase 05 e representados na tabela 1. Com isto foi possível agrupar as 503 ações apresentadas pelos especialistas em 59 ações observando a integração com as demais Rotas Estratégicas Setoriais. Para a validação desta etapa, foram realizadas duas rodas de análise dos conteúdos entre os consultores e representantes da FIESC, FECOMERCIO SC \& SEBRAE/SC entre os meses de setembro e outubro de 2016 e, também por avaliadores externos que não participaram das fases anteriores.

O Roadmap foi construído observando as ações de curto, médio e longo prazo. Para as ações de curto prazo teve como alicerce as rotas estratégicas integradas da Economia do Mar, Energia, Meio Ambiente e Tecnologia da Informação e Comunicação.

O foco central destas ações foi o Modelo de Gestão (planejamento estratégico, integração política, instância de governança, orçamento, alianças estratégicas <clusters>), apoiado por cinco outras ações sendo, Convênio (observatório/inteligência em turismo, parceria público-privada, qualificação/formação de pessoas, planejamento longo prazo), Fomento (funturismo, icms/iss turístico, parceria público-privada e FAPESC), Legislação (política para o turismo, análise legal das atividades turísticas e zonas especiais de interesses turísticos), Inovação (observatório/inteligência em 
Actas del Seminario Internacional Destinos Turísticos Inteligentes:

nuevos horizontes en la investigación y gestión del turismo

Universidad de Alicante, 26 y 27 de octubre de 2017

turismo, parceria público-privada, FAPESC, programa catarinense de inovação), e Sustentabilidade (saneamento básico, qualidade das águas e energia limpa) (FIESC, FECOMERCIO SC \& SEBRAE/SC, 2016).

Para as ações de médio prazo teve como alicerce as rotas estratégicas integradas Energia, Meio Ambiente e Tecnologia da Informação e Comunicação. O foco central destas ações foi a Zonas Especiais de Interesse Turístico (consolidação de zonas especiais de interesse turístico em todas as regiões turísticas do estado, produtos turísticos para investimentos).

Conta com apoio de Com apoio de 05 outras ações, como Inovação (Open Government Data, incubadoras focadas em P\&D em turismo nos centros de inovação, sistema de inteligência e negócios, multiplataformas de distribuição, gestão de risco), Legislação (turismo como disciplina curricular nas escolas, incentivos à PME e MEl para o setor de turismo, política de Open Government Data, sistema de gestão pública de turismo), Profissionalização (inserção do turismo como disciplina escolar, indicadores profissionais, qualidade na prestação de serviços, observatório de turismo e contratação de turismólogos), Sustentabilidade (Energias renováveis, parâmetros de medição, gestão de resíduos) e Modelo de gestão (sistema de gestão pública de turismo, gestão dos planos diretores para zonas especiais de interesse turístico, plano integral de qualidade e valorização da cultura e conservação do meio ambiente) (FIESC, FECOMERCIO SC \& SEBRAE/SC, 2016).

$E$ as ações de longo prazo que contam com alicerce das rotas estratégicas integradas Meio Ambiente e Tecnologia da Informação e Comunicação, tendo como ação principal Destino Turístico Inteligente (consolidar Santa Catarina como DTI no Brasil).

Conta com apoio de Com apoio de 05 outras ações, como Incentivo Fiscal (política de incentivos fiscais, MEI, PME, Incubadoras e Startup), aquisição de insumos <produtos/tecnologias> para o setor de turismo, funturismo), Integração (produtos complementares por regiões turísticas, plataforma de negócios em turismo <cadeia produtiva>, sistemas modais, setores público, privado, terceiro setor e ensino/pesquisa), Mobilidade (Secretaria de Estado de Turismo no processo de discussão de mobilidade do Estado, integração dos diferentes modais, incentivo do setor produtivo no planejamento estratégico modais), e Sutentabilidade (visão da rota estratégica setorial Economia do Mar, e Energia) (FIESC, FECOMERCIO SC \& SEBRAE/SC, 2016).

Por fim, adaptando-se o modelo da Austrália - Turismo 2020, foram estruturadas as ações (curto, médio e longo prazo) para que fossem, a 
Actas del Seminario Internacional Destinos Turísticos Inteligentes:

nuevos horizontes en la investigación y gestión del turismo

Universidad de Alicante, 26 y 27 de octubre de 2017

posterior, definidos os objetivos, as ações, identificados os resultados esperados e estabelecer metas conforme representado na figura 8.

Figura 8. Construção Futura da Execução das Ações

AÇÖES DE CURTO PRAZO

\begin{tabular}{|c|c|c|c|c|c|}
\hline \multicolumn{6}{|c|}{ Macroestratéglas } \\
\hline MODELO DE GESTÄO & LEGISLAÇĀ̄o & SUSTENTABILIDADE & CONVÊNIOS & INOVAÇĀOO & FOMENTO \\
\hline \multicolumn{6}{|c|}{ Objetivos } \\
\hline \multicolumn{6}{|c|}{ AÇŌES DE MÉDIO PRAZO } \\
\hline \multicolumn{6}{|c|}{ Macroestratégias } \\
\hline 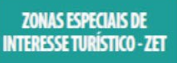 & $\begin{array}{l}\text { MODELOO } \\
\text { DE GESTÄOO }\end{array}$ & LEGISLAÇĀo & PROFISSIONALIZAÇĀO & InOVAçä̃o & SUSTENTABILIDADE \\
\hline \multicolumn{6}{|c|}{ Objetivos } \\
\hline
\end{tabular}

AÇÕES DE LONGO PRAZO

\begin{tabular}{|c|c|c|c|}
\hline \multicolumn{3}{|c|}{ Macroestratéglas } \\
\hline $\begin{array}{c}\text { DESTINO TURISTICO } \\
\text { INTELIGENTE }\end{array}$ & INCENTIVOS FISCAIS & MOBILIDADE & SUSTENTABILIDADE \\
\hline & Objetivos \\
\hline
\end{tabular}

Fonte: Adaptado de FIESC, FECOMERCIO SC \& SEBRAE (2016)

\section{Considerações finais}

Pela primeira fez no Estado de Santa Catarina e, poucas vezes observado em outros Estados, o projeto não teve como ator principal a Secretaria de Estado de Turismo, ao contrário, foi coadjuvante.

Com a união de três entidades que representam o setor industrial, comercial e serviços, respectivamente, FIESC, FECOMERCIO SC e SEBRAE/SC, o projeto foi realizado integrando inicialmente consultores ligados a quatro Universidades caracterizadas em pesquisa e desenvolvimento.

A construção do projeto tendo como base referencial os conceitos e modelos de DTI, de plataforma de negócios e dois modelos realizados por, respectivamente, Portugal e Austrália, permitiu a discussão e a construção de fatores críticos e suas ações sem vícios de outros projetos já realizados.

Como resultado principal foi a definição da consolidação do Estado de Santa Catarina como DTI para o ano de 2022 observando a sustentabilidade 
Actas del Seminario Internacional Destinos Turísticos Inteligentes:

nuevos horizontes en la investigación y gestión del turismo

Universidad de Alicante, 26 y 27 de octubre de 2017

(integração com as visões estratégicas de outras rotas), incentivo fiscal (para micros, pequenos e médios empreendedores, e funturismo), mobilidade (incentive do setor produtivo no planejamento estratégicos de modais) e integração (setor público, privado, ensino/pesquisa, terceiro setor, munícipes).

A implementação das ações apresentada está em fase da construção de um consórcio multidisciplinar envolvendo setor público (legislativo, executivo e judiciário), federações setoriais, instituições de ensino superior, centros de inovação, e comunidade para o desenvolvimento tecnológico desta plataforma de DTI.

\section{Referências}

Australia Government (2011). Tourism 2020: Whole of government working with industry to achive Australia's tourism potencial. December, 2011. Disponivel em: http://www.tourism.australia.com/documents/Tourism_2020_overview. pdf.

Biz, A. (2014). Plataforma de Negócios em Turismo para Foz do Iguaçu. Universidade Federal do Paraná: Curitiba.

Buhalis, D. \& Amaranggana, A. (2015) Smart Tourism Destinations Enhancing Tourism Experience Through Personalisation of Services. In. lis Tussyadiah \& Alessandro Inversini (Ed.). Information and Communication Technologies in Tourism 2015: Proceedings of the International Conference in Lugano, Switzerland, February 3-6, pp.377-391.

Del Chiappa, G. \& Baggio, R. (2015) Knowledget ransferin smart tourism destinations: Analyzing the effects of a network structure. Journal of Destination Marketing \& Management, v. 4, pp. 145-150. Disponível em: http://dx.doi.org/10.1016/j. jdmm.2015.02.001.

FIESC, FECOMÉRCIO SC \& SEBRAE/SC. (2016). Rotas estratégicas setoriais para a indústria catarinense 2022: Turismo. Florianópolis: FIESC.

Gawer, A. (2010) Towards a General Theory of Technological Platforms. Opening Up Innovation: Strategy, Organization and Technology. Imperial College London Business School, June 16-18,. Disponível em < http://www2.druid.dk/conferences/viewpaper. . php?id=501981\&cf=43>.

Gretzel, U., Werthner, H., Koo, C. \& Lamsfus, C. (2015). Conceptual foundations for understanding smart tourism ecosystems. Computers in Human Behavior, vol. 50, pp. 558-563. Disponível em: http://www.sciencedirect.com/science/article/ pii/S0747563215002332 
Actas del Seminario Internacional Destinos Turísticos Inteligentes:

nuevos horizontes en la investigación y gestión del turismo

Universidad de Alicante, 26 y 27 de octubre de 2017

Gretzel, U., Sigala, M., Xiang, Z. \& Koo, C. (2015). Smart tourism: foundations and developments. Electronic Markets, vol. 25, n. 3, pp. 179-188. Disponível em: https://link.springer.com/article/10.1007/s12525-015-0196-8

INVAT.TUR (2015). Destinos Turísticos Inteligentes: Manual Operativo para la Configuración de los Destinos Turísticos Inteligentes. Mar. 2015. Disponível em: http://www.thinktur.org/media/Manual-de-destinos-tur\%C3\%ADsticos-inteligentes.pdf

Ivars, J.; Solsona, J.; Giner, D. (2016). Gestión turística y tecnologías de la información y la comunicación (TIC): el nuevo enfoque de los destinos inteligentes. Documents d'Anàlisi Geogràfica, vol. 62/2, pp. 327-346.

López de Ávila, A.; García, S. (2015). Destinos Turísticos Inteligentes. Revista Economía Industrial, n. 395, pp. 61-70.

López de Ávila, A. (2015). Smart destinations: XXI century tourism. Presented at the ENTER2015 Conference on Information and Communication Technologies in Tourism, Lugano, Switzerland, February 4-6.

Portugal. Turismo de Portugal (2014). Turismo 2020: Plano de Ação para o Desenvolvimento do Turismo de Portugal. Disponível em: http://estrategia.turismodeportugal.pt/sites/default/files/Turismo2020_Parte\%20I_mercados\%20-\%20 SWOT.pdf

SEGITTUR. (2012). Destinos Turísticos Inteligentes. Madrid: SEGITTUR. Disponível em: <http://www.segittur.es/es/proyectos/proyecto-detalle/Destinos-Tursticos-Inteligentes-00006/\#.WM9IcTsrLIV>. Acessado em: 13 jan. 2015.

Solsona, J.; Giner, D. (2015) Cómo desarrollar un destino turístico inteligente. Investigación. TecnoHotel, n. 465, abril 2015, pp. 48-49. Disponível em: http://issuu. com/peldano/docs/tecnohotel_465/1?e=1189233/12514138

Todesco, J. L. et. al. (2014) Ações de gestão do conhecimento para o aprimoramento da política nacional de turismo: arcabouço e diretrizes (Apêndice A). Fevereiro 2014. Projeto de P\&D realizado pelo Programa de Pós-Graduação em Engenharia e Gestão do Conhecimento. Florianópolis: UFSC.

Vargas-Sánchez, (2016). A. Exploring the Concept of Smart Tourist Destination. Elightening Tourism. A Pathmaking Journal, v. 6. N. 2, pp. 178-196. Disponível em: http://uhu.es/publicaciones/ojs/index.php/et/article/view/2913/2625.

World Economic Forum (2015). The Travel \& Tourism Competitiveness Report 2015: Growth through Shocks. Disponível em:<http://www3.weforum.org/docs/TT15/ WEF_Global_Travel\&Tourism_Report_2015.pdf>. Acesso em: 14 jun. 2016. 
Actas del Seminario Internacional Destinos Turísticos Inteligentes: nuevos horizontes en la investigación y gestión del turismo Universidad de Alicante, 26 y 27 de octubre de 2017

World Economic Forum (2017). The Travel \& Tourism Competitiveness Report 2017. Disponível em: https://www.weforum.org/reports/the-travel-tourism-competitiveness-report-2017 